\title{
Characterization of Storage Material in Cultured Fibroblasts by Specific Lectin Binding in Lysosomal Storage Diseases
}

\author{
ISMO VIRTANEN, ${ }^{(34)}$ PETER EKBLOM, PEKKA LAURILA, STIG NORDLING, KARI O. RAIVIO, \\ AND PERTTI AULA \\ Department of Pathology, Children's Hospital and Laboratory of Prenatal Genetics, Department of Obstetrics and \\ Gynecology, University of Helsinki, Helsinki, Finland
}

\begin{abstract}
Summary
The lysosomal storage material in cultured fibroblasts from patients with various lysosomal storage diseases was characterized by fluorescence microscopy using lectins specific for different saccharide moieties. In normal fibroblasts and cultured amniotic fluid cells lectins specific for mannosyl and glucosyl moieties, Con $A$ and LcA gave a bright perinuclear cytoplasmic staining corresponding to the localization of endoplasmic reticulum in the cells. All other lectins stained the Golgi apparatus as a juxtanuclear reticular structure.

In fucosidosis fibroblasts, only lectins specific for fucosyl groups LTA and UEA, distinctly stained the lysosomal inclusions. The lysosomes in mannosidosis fibroblasts did not react with Con $A$ and LcA, both specific for mannosyl moieties of glycoconjugates, but were brightly labeled with WGA, a lectin specific for $\boldsymbol{N}$-acetyl glucosaminyl moieties. In I-cell fibroblasts, the numerous perinuclear phase-dense granules, representing abnormal lysosomes, were labeled with every lectin used. In fibroblasts from patients with Salla disease, a newly discovered lysosomal storage disorder, the lysosomes were brightly stained only with LPA, indicating the presence of increased amounts of sialic acid residues in the lysosomal inclusions.
\end{abstract}

\section{Speculation}

Staining of cultured cells with sugar-specific lectins may reveal interesting aspects on the pathogenesis of lysosomal storage phenomenon. In some instances, the method can be of use as an auxiliary technique in prenatal diagnosis of lysosomal storage diseases.

Lysosomal storage disorders are inherited diseases of metabolism caused by defects in lysosomal hydrolases and characterized by intralysosomal accumulation of undegraded and partially catabolized macromolecules $(11,14,25)$. The individual disorders can be diagnosed on the basis of urinary excretion of abnormal metabolites or by enzyme assay $(11,14)$. The fibroblasts cultured from a patient with a given lysosomal disorder usually express the enzyme defect even though the cultured cells do not show the storage phenomenon in all instances.

Although ultrastructural features of the storage lysosomes can be of help in distinguishing lysosomal disorders, a number of them present similar vacuoles with nondistinct contents in electron microscopy $(9,18,21,24,28)$. Histochemical methods have also been of limited value in the characterization of the storage vacuoles $(9,11,18,21,23,24,28)$.

Many of the lysosomal storage diseases involve a defect in enzymes degrading glycoproteins, glycolipids, and glycosaminoglycans, and the carbohydrate sidechains are thus at least partially retained in the stored material $(11,23,25,26)$. The saccharide moieties of glycoconjugates act as binding sites for lectins, plant or animal proteins specific for different saccharide moieties (4). We have recently developed a method enabling visualization of intracellular lectin binding sites in fluorescence microscopy (15, 32). The aim of the present study was to evaluate whether the saccharide specificity of lectins can be utilized for characterization of the storage phenomenon in cultured fibroblasts from patients with various lysosomal storage diseases.

\section{MATERIALS AND METHODS}

\section{MUTANT CELL LINES}

Fibroblast cultures were initiated from small skin biopsy specimens using standard cell culture techniques and Ham's F-10 medium supplemented with $10 \%$ fetal calf serum and antibiotics. Skin biopsy was taken from one patient with mannosidosis, I-cell disease (mucolipidosis II) and five patients with Salla disease. An I-cell disease cell line (GM-3066) was also obtained from the Human Genetic Mutant Cell Repository, Camden, NJ. The diagnosis of mannosidosis was based on clinical and enzyme studies as well as demonstration of mannose-containing oligosaccarides in urine (2). I-cell disease was diagnosed by clinical, electron microscopic and cell culture studies (3). The diagnosis of Salla disease was based on clinical findings, electron microscopy, and demonstration of excessive amounts of free sialic acid in urine ( 1 , 27). The fibroblast cell line from a patient with fucosidosis (5) was obtained through the courtesy of Dr. Sverre Lie (Oslo, Norway). The enzyme defects of all mutant cell lines used in the present study were verified by enzyme assays. Both adult and embryonic human fibroblast cultures were used as controls. Normal amniotic fluid cell cultures were grown in the same tissue culture conditions from amniotic fluid samples obtained for fetal karyotype determination at 15th or 16th wk of gestation.

Accumulation of phagolysosomes in normal cultured fibroblasts was induced by allowing the cells to ingest latex particles $(0.5 \mu \mathrm{m}$; Polysciences Inc., Warrington, PA) for $24 \mathrm{hr}$. Thereafter, the cells were trypsinized and replated on glass coverslips (16). For phase contrast and fluorescence microscopy, the cells were grown on small glass coverslips for 5 to 7 days and fixed in 3.5\% paraformaldehyde made in $0.1 \mathrm{M}$ phosphate buffer, $\mathrm{pH}$ 7.2. Thereafter, the coverslips were washed in phosphate-buffered saline (PBS) and treated with $0.05 \%$ Nonidet NP-40 to make the cells permeable to fluorescent lectins (15).

\section{LECTINS AND THEIR SPECIFICITY}

The following lectins were used either as fluorescein isothiocyanate (FITC) or tetramethyl rhodamine isothiocyanate (TRITC) conjugates: concanavalin $\mathrm{A}(\mathrm{Con} \mathrm{A})$, and Lens culinaris agglutinin 

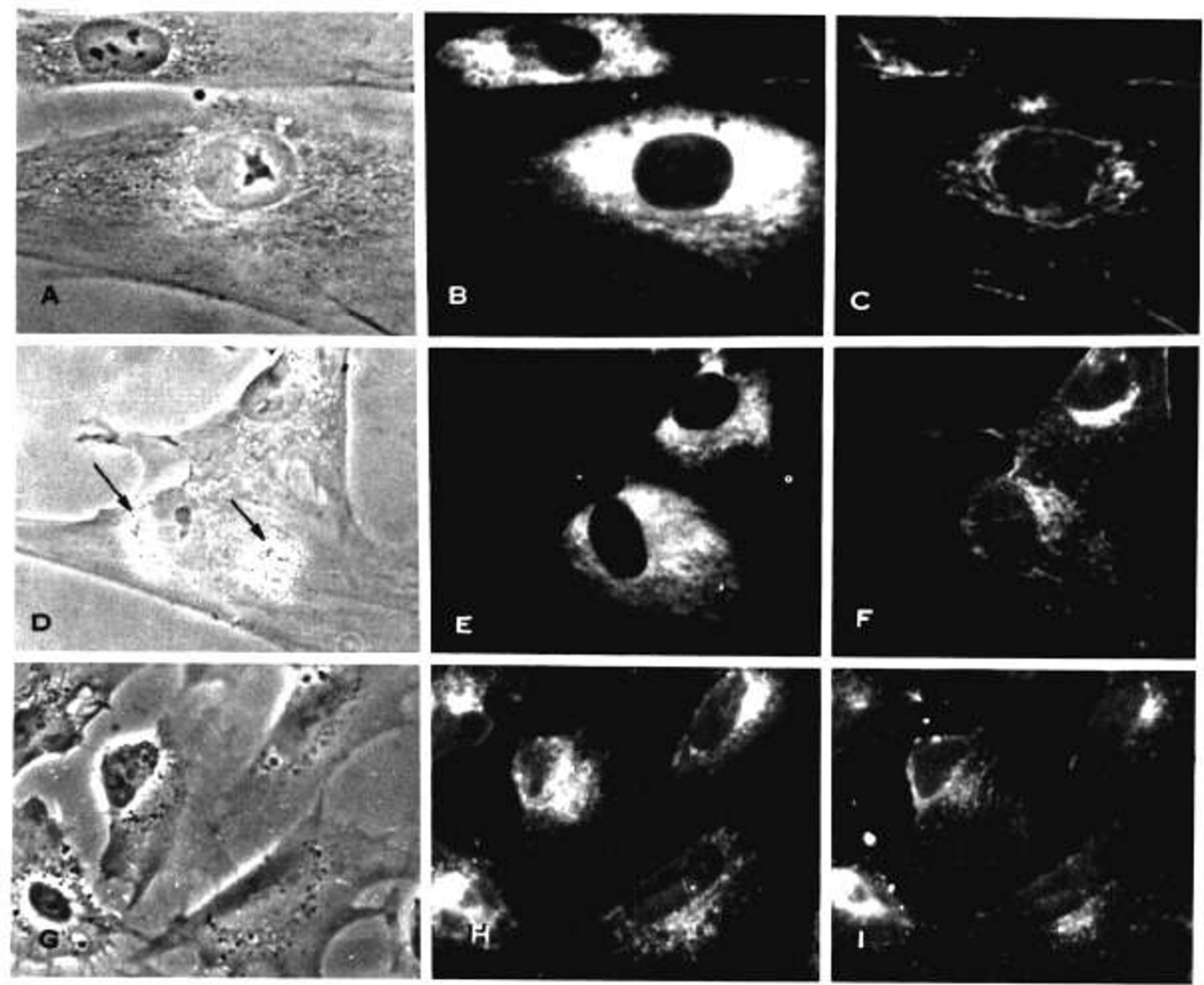

Fig. 1. Lectin staining of cultured normal skin fibroblasts and amniotic fluid cells. All figures, $\times 400$.

Fibroblasts seen in phase contrast $(A)$ and fluorescence microscopy after double-staining with FITC-Con A $(B)$ and TRITC.WGA $(C)$. Bright perinuclear cytoplasmic staining $(B)$ and the distinctly different tluorescence (C).

Cultured fibroblasts after endocytosis of $0.5-\mu \mathrm{m}$ Latex particles seen in phase contrast $(D)$ and fluorescence microscopy after double-staining of the same cells with FITC-Con A $(E)$ and TRITC-WGA $(F)$. Perinuclear accumulations of Latex particles $(D$, arrows) are only faintly stained with TRITCWGA $(F)$ but are not labeled with FITC-Con A as seen in $E$.

Cultured amniotic fluid cells seen in phase-contrast microscopy $(G)$ and double-stained with FITC-Con A $(H)$ and TRITC-WGA $(I)$. Distinct perinuclear staining $(H)$ and the juxtanuclear fluorescence $(I)$.

(LcA), both specific for mannosyl and glucosyl groups; wheat germ agglutinin (WGA), specific for $N$-acetyl glucosamine and its oligomers; Ricinus communis agglutinins 60 (RCA 60) and 120 (RCA 120), specific for galactose and $N$-acetyl galactosamine moieties; Lotus tetragonolobus agglutinin (LTA) and Ulex europaeus agglutinin (UEA), specific for fucose moieties; and Limulus polyphemus agglutinin (LPA), specific for sialic acid moieties. The lectin conjugates were purchased from E-Y Laboratories (San Mateo, CA), Vector Laboratories (Burlingame, CA), Miles Laboratories (Elkhart, IN), and Sigma Chemical Co. (St. Louis, MO). The lectin conjugates were used at concentrations of 100 to 150 $\mu \mathrm{g} / \mathrm{ml}$ in PBS supplemented with $\mathrm{Ca}^{2+}$ and $\mathrm{Mg}^{2+}$ for $30 \mathrm{~min}$. Thereafter, the specimens were thoroughly washed in PBS and embedded in Veronal-glycerol buffer, pH 8.4, or PBS (RCA 60 and RCA 120).

The specificity of the lectins used has been thoroughly reviewed by Brown and Hunt (4) and verified also in the present study by preincubation of the lectin conjugates in a $0.2 \mathrm{M}$ solution of the respective haptenic monosaccharides. After such preincubation, all the lectin conjugates gave negative staining results with the cultured cells in fluorescence microscopy.

For fluorescence and phase contrast microscopy a Zeiss universal microscope was used equipped with an epi-illuminator III RS filters for FITC and TRITC fluorescence and phase contrast
Table 1. Staining of lysosomes with fluorochrome-conjugated lectins in normal and mutant cell lines

\begin{tabular}{|c|c|c|c|c|c|}
\hline Cell line & $\begin{array}{c}\text { Con } A \\
\text { and LcA }\end{array}$ & WGA & $\begin{array}{l}\text { RCA } 60 \\
\text { and } 120\end{array}$ & $\begin{array}{c}\text { LTA }^{\prime} \text { and } \\
\text { Ulex } \\
\text { europaeus } \\
\text { agglutinin }\end{array}$ & LPA \\
\hline $\begin{array}{l}\text { Normal fibroblasts } \\
\text { (Latex-phagoly- } \\
\text { sosomes) }\end{array}$ & - & $\mp$ & $\mp$ & - & - \\
\hline Amniotic fluid cells & - & - & - & - & - \\
\hline Mannosidosis & - & + & - & - & - \\
\hline Fucosidosis & - & - & - & + & - \\
\hline Salla disease & - & - & - & - & + \\
\hline 1-cell disease & + & + & + & + & + \\
\hline
\end{tabular}

' LTA, lotus tetragonolobus agglutinin.

optics. The abscence of autofluorescence was confirmed by the use of UV and green excitation light.

\section{RESULTS}

In cultured normal adult fibroblasts, both Con $\mathrm{A}$ and LcA, lectins specific for mannosyl and glucosyl moieties, gave a bright 

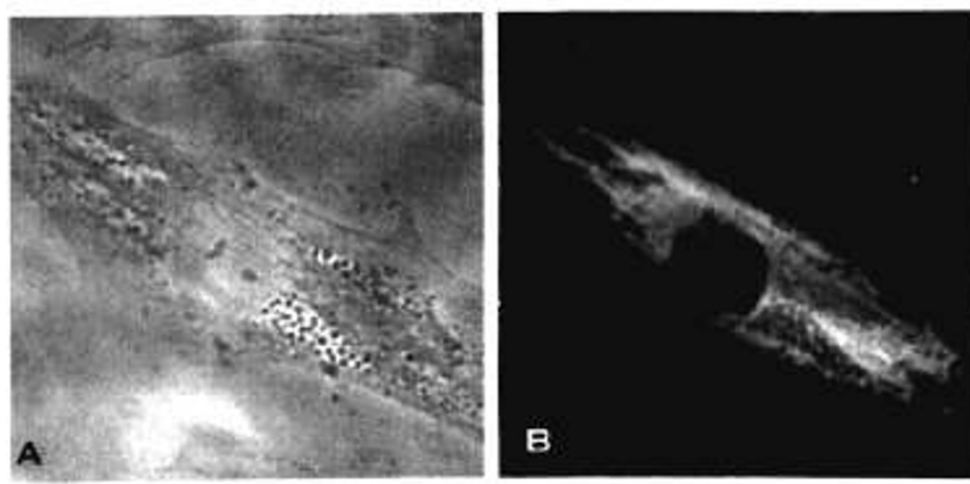

B
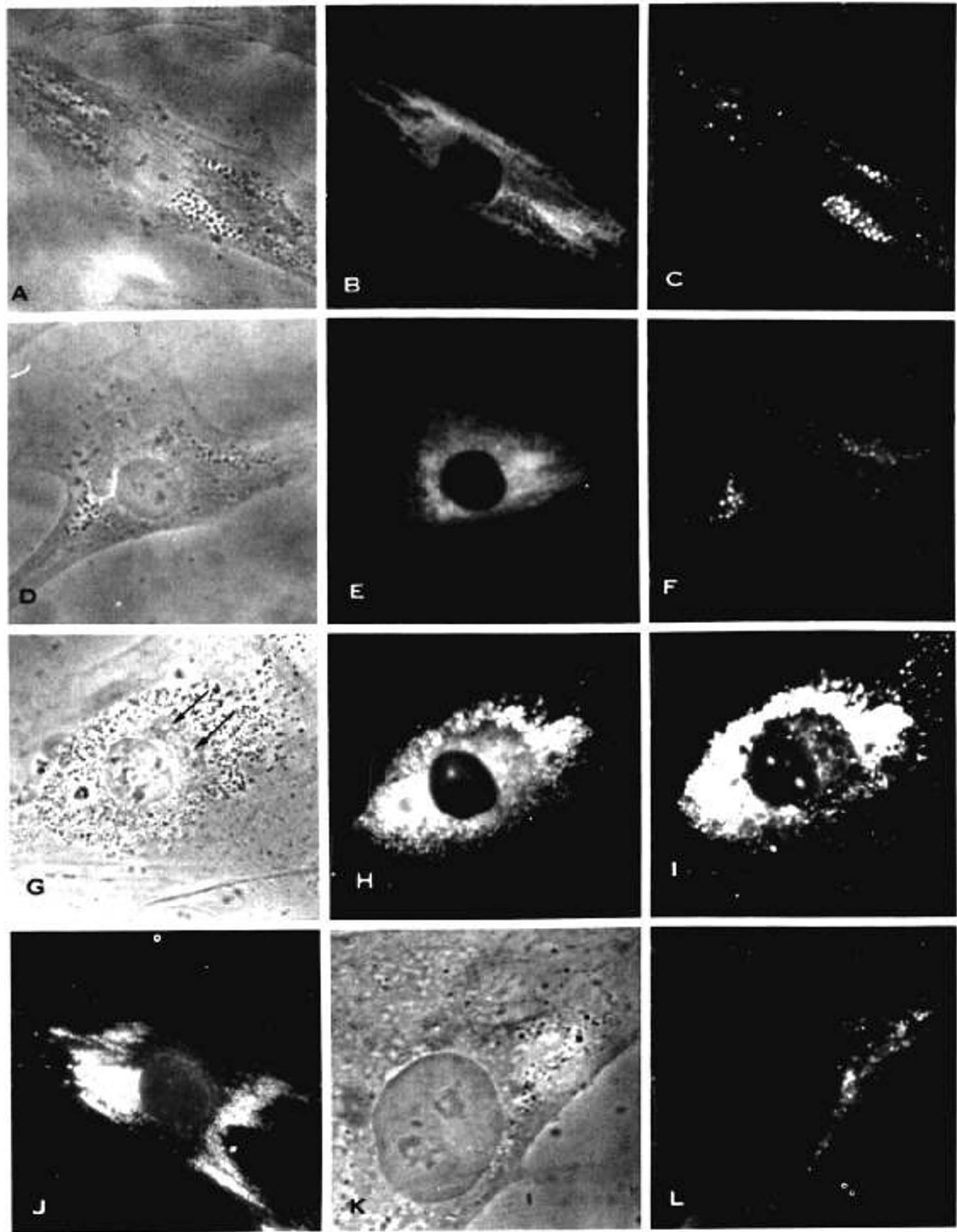

Fig. 2. $A$ to $C$, cultured skin fibroblasts from a patient with fucosidosis seen in phase contrast $(A)$ and fluorescence microscopy after double staining with FITC-Con $\mathrm{A}(B)$ and TRITC-Ulex europaeus agglutinin $(C)$. The phase-dense lysosomal granules $(A$, arrows) are only stained with TRITC-Ulex europaeus agglutinin ( $C$ ), whereas FITC-Con A only stains the typical perinuclear region of endoplasmic reticulum in these cells $(B)$.

$D$ to $F$, cultured skin fibroblasts from a patient with mannosidosis seen in phase contrast $(D)$ and fluorescence microscopy after double staining with FITC-Con A $(E)$ and TRITC-WGA $(F)$. Typical perinuclear cytoplasmic fluorescence obtained with FITC-Con A $(E)$ and distinct cytoplasmic granular fluorescence obtained with TRITC-WGA $(F)$.

$G$ to $J$, cells from a patient with I-cell disease seen in phase contrast $(G)$ and fluorescence microscopy after double staining of the same cells with FITC-Con A $(H)$ and TRITC-WGA $(I)$ and after staining with FITC-LPA $(J)$. The granular cytoplasmic accumulations are brightly stained with all lectins used as seen with FITC-Con A $(H)$, TRITC-WGA $(I)$, and also with FITC-LPA $(J)$. The granule-free juxtanuclear area seen in $G(a r r o w s)$ is apparently occupied by the reticular Golgi region as seen in $I$.

$K$ and $L$, cultured cells from a patient with Salla disease seen in phase contrast $(K)$ and fluorescence microscopy after staining with FITC-LPA $(L)$. The phase-dense cytoplasmic granules are brightly stained with this lectin. 
perinuclear cytoplasmic staining (Fig. $1, A$ and $B$ ), corresponding to the localization of endoplasmic reticulum $(15,32)$. In contrast, all other lectins stained the Golgi apparatus (32) as a juxtanuclear reticular structure (Fig. 1C). Inasmuch as only a few lysosomes were detectable in normal cells, the number of phagolysosomes was increased by allowing the cells to phagocytize latex particles (Fig. 1, $D$ to $F$ ). The perinuclearly arranged latexphagolysosomes were not stained with Con A (Fig. $1 E$ ) but were faintly stained with WGA (Fig. $1 F$ ) and RCA 60 and RCA 120 (cf. Table 1). Staining with LPA, specific for sialic acid moieties, was no detectable. The cultured amniotic fluid cells showed a similar pattern of lectin staining as the skin fibroblasts with the characteristic perinuclear endoplasmic reticulum-type fluorescence with FITC-Con A (Fig. I, $G$ and $H$ ) and different juxtanuclear Golgitype staining with TRITC-WGA (Fig. $1 \Gamma$ ).

In fibroblasts from the patients with fucosidosis, only lectins specific for fucosyl groups, lotus tetragonolobus agglutinin and Ulex europaeus agglutinin, distinctly stained the lysosomal inclusions (Fig. 2, $A$ and $C$ ). Other lectins only gave either the typical endoplasmic reticulum (Con A and LcA; Fig. 2B) or Golgi (all other lectins) labeling.

The lysosomes in fibroblasts from the patients with mannosidosis did not react with Con A or LcA (Fig. 2, D and E), both specific for mannosyl moieties of glycoconjugates. Instead, these lectins stained the region of the endoplasmic reticulum (Fig. $2 E$ ) as in normal cells. WGA, specific for $N$-acetyl glucosaminyl moieties, on the other hand, brightly labeled the lysosomal structures found in mannosidosis-fibroblasts (Fig. $2 F$ ).

In cultured fibroblasts from both I-cell disease cell lines, the numerous perinuclear phase-dense granules, representing abnormal lysosomes, were labeled with every lectin used (Fig. 2, $G$ to $J$ ). A granule-free perinuclear crescent (Fig. $2 G$ ) occupied by reticular structure representing the Golgi apparatus (Fig. $2 I$ ) was clearly seen in all cells of I-cell disease ( $c f$. Refs. 17 and 30).

In fibroblasts from patients with Salla disease, the lysosomes were brightly stained only with LPA (Fig. 2, $K$ and $L$ ), indicating the presence of increased amounts of sialic acid residues in the lysosomal inclusions.

The results from staining the lysosomes in various mutant cell lines with FITC- or TRITC-coupled lectins are summarized in Table 1.

\section{DISCUSSION}

Both ultrastructural and histochemical methods have proved to be of little use in the elucidation of abnormal lysosomal storage $(9,11,18,21,24,28)$. In the present study, we have shown that in cultured fibroblasts from patients with a number of lysosomal storage diseases, lysosomal inclusions present characteristic lectinbinding affinity specified by the oligosaccharide structure of the storage material and different from that found in experimentally produced lysosomal accumulations.

In fucosidosis, the basic defect is deficiency of lysosomal $\alpha-\mathrm{L}-$ fucosidase which results in accumulation of fucose-containing glycopeptides and glycolipids in lysosomes of several tissues (5, 8 ). In agreement with this concept, our findings showed that only lectins specific for fucosyl moieties bind to lysosomes in fucosidosis-fibroblasts. Unexpectedly, however, lectins specific for mannosyl moieties did not bind at all to lysosomes in fibroblasts from the patient with mannosidosis. In mannosidosis, the defect involves $\alpha$-mannosidase, one of the enzymes splitting mannosyl groups from oligosaccharides, and the result is accumulation in tissues and excretion in urine of mannose-rich oligosaccharides $(6,13,22,25,31)$. Cultured fibroblasts from patients with mannosidosis also accumulate increased amounts of mannose-containing oligosaccharides (22). However, both urinary and fibroblast oligosaccharides in mannosidosis contain $N$-acetyl glucosamine and mannose in a $3: 1$ ratio (13), which could be relevant to our finding that the lysosomes in mannosidosis were stained with WGA specific for $N$-acetyl glucosamine residues. Whether the lack of staining of mannosidosis lysosomes with mannose-specific lectins (Con A and LcA) depends on some steric hindrance or on leakage of low-molecular weight storage material during specimen preparation remains to be elucidated.

The basic enzyme deficiency in I-cell disease (mucolipidosis II) is still unknown, but most of the lysosomal hydrolases show decreased intracellular activity $(12,14,20,25)$. Extensive accumulation of lysosomal inclusions have been considered typical for cells with this disease $(3,10,17,18,20,30)$. However, no specific abnormal metabolites have so far been recovered from the inclusions $(14,18,20,26)$. Recently, I-cell disease fibroblasts were found to contain increased amounts of sialic acid when compared to normal fibroblasts (29). Our results show that lysosomes in Icell fibroblasts bind extensively lectins specific for all saccharide moieties found in glycoproteins and glycolipids which suggest the presence of undegraded oligosaccharides in the lysosomes. The location of lysosomal inclusions in I-cell disease around the Golgi apparatus was clearly different from other mutant cell lines, suggesting that the pathogenesis of lysosomal accumulation in Icell disease differs from that of other lysosomal storage diseases.

Salla disease is a recently described lysosomal storage disease of unknown etiology, characterized by a 10 -fold increase of free sialic acid in the urine $(1,27)$. Interestingly, only LPA, specific for sialic acid moieties in glycoconjugates, bound extensively to the inclusions in all cell lines from patients with this disease. Taking also the abnormal urine findings into account, it appears that the basic defect in Salla disease may be related to the metabolism of sialyl glycoconjugates. Our results also suggest that lectin staining of cultured amniotic fluid cells might prove to be suitable for the prenatal diagnosis of Salla disease, which at the present is not possible by any other technique. In other lysosomal storage diseases, lectin staining of cultured amniotic fluid cells could be used as an auxiliary method for prenatal diagnosis, although the final diagnosis should always be based on the specific enzyme assays.

In summary, our results show that lectins, which have been used in morphologic and biochemical studies of glycoconjugates in cells and tissues, may be of value in the elucidation of the pathogenesis and possibly in the diagnosis of certain lysosomal diseases.

\section{REFERENCES AND NOTES}

1. Aula, P., Autio, S., Raivio, K. O., Rapola, J., Thodén, C-J., Koskela, S-L., and Yamashina, I.: Salla disease. A new lysosomal storage disorder. Arch. Neurol. 36: 88 (1979).

2. Autio, S., Norden. N. E., Öckerman, P. A., Riekkinen. P., Rapola, J., and Louhimo, T.: Mannosidosis: clinical, fine-structural and biochemical findings in three cases. Acta Pediatr. Scand. 62: 555 (1973).

3. Aula. P., Rapola, J., Autio. S., Raivio, K., and Karjalainen, O.: Prenatal diagnosis and fetal pathology of I-cell disease (Mucolipidosis type II). J. Pediatr., 87: 221 (1975).

4. Brown, J. E., and Hunt, R. C.: Lectins. Int. Rev. Cytol., 52: 277 (1977).

5. Dawson, G., and Spranger, J. W.: Fucosidosis: a glycosphingolipidosis. N. Engl. J. Med.. 285: 122 (1971)

6. Desnick, R. J., Sharp, H. L., Grabowski, G. A., Brunning. R. D., Quie. P. G. Sung, J. H., Gorlin. R. J., and Ikonne, J. U.: Mannosidosis: clinical, morphologic, immunologic and biochemical studies. Pediatr. Res.. 10: 985 (1976).

7. Dulaney. J. T.: Binding interactions of glycoproteins with lectins. Mol. Cell. Biochem., 21: 43 (1979).

8. Durand. P.: Progress and problems on fucosidosis and mucolipidosis. In: V Zambotti, G. Tettamani, M. Arrigoni: Glycolopids. Glycoproteins and Mucopolysaccharides of the Nervous System, pp. 293-303 (Plenum Press, New York. 1972).

9. Dustin. P.. Tondeur. M., and Libert. J.: Metabolic and storage diseases. In: J. V. Johanneses: Electron Microscopy in Human Medicine. Vol. 2. pp. 151-245 (McGraw-Hill Book Co.. New York, 1978).

10. Hanai. J., Leroy, J.. and $\mathrm{O}^{\prime} B$ rien. J.: Ultrastructure of cultured fibroblasts in Icell disease. Am. J. Dis. Child. 122: 34 (1971)

11. Hers, H. G., and van Hoof. F. (eds.): Lysosomes and Storage Diseases. (Academic Press, Inc.. New York, 1973).

12. Hickman, S., and Neufeld. E. F.: A hypothesis for I-cell disease: defective hydrolases that do not enter lysosomes. Biochem. Biophys. Res. Commun, 49: 992 (1972).

13. Kistler. J. P.. Lott. I. T., Kolodny, E. H., Friedman, R. B., Nerasian. R., Schnur. J.. Mihm. M. C.. Dvorak, A. M., and Dickersin. R.: Mannosidosis. New clinical presentation. enzyme studies and carbohydrate analysis. Arch. Neurol.. 34 : 45 (1977). 
14. Kolodny, E. H.: Lysosomal storage diseases. N. Engl. J. Med., 294: 1217 (1976)

15. Laurila. P., Virtanen, I., Wartiovaara, J., and Stenman, S.: Fluorescent antibodies and lectins stain intracellular structures in fixed cells treated with nonionic detergent. J. Histochem. Cytochem., 78: 251 (1978).

16. Laurila, P., Wartiovaara, J., and Stenman, S.: Fibronectin expression is determined by the genotype of the transformed parental cell in heterokaryons between normal and transformed fibroblasts. J. Cell. Biol., 80: 118 (1979).

17. Leroy, J. G., and DeMars, R. I.: Mutant enzymatic and cytological phenotypes in cultured human fibroblasts. Science (Wash. D.C.). 157: 804 (1967).

18. Martin, J. J., Leroy, J. G., Farriaux, J. P., Fontaine, G., Desnick, R. J., and Cabell, A.: I-cell disease (Mucolipidosis II). A report on its pathology. Acta Neuropathol., 33: 285 (1975).

19. McKusick, V. A. Neufeld, E. F., and Kelly, T. E.: The mucopolysaccharide storage diseases. In: J. B. Stanbury, J. B. Wyngaarden, D. S. Fredrickson: The Metabolic Basis of Inherited Disease. pp. 1282-1307 (McGraw-Hill Book Co., New York, 1978).

20. Neufeld, E. F.: The biochemical basis for mucopolysaccharidoses and mucolipidoses. In: A. G. Steinberg, A. G. Bearn: Progress in Medical Genetics. Vol. 10. pp. 81-101. (Grune \& Stratton, New York, 1974)

21. O'Brien. J. S. Bernett. J., Veath, L., and Paa. D.: Lysosomal storage disorders. Diagnosis by ultrastructural examination of skin biopsy specimens. Arch Neurol., 32: 592 (1975).

22. Öckerman, P. A.: Mannosidosis. In: H. G. Hers, F. Van Hoof: Lysosomes and Storage Diseases. (New York. Academic Press, Inc., 1973).

23. Öckerman P. A.. Nordén. N. E., and Szabo. L.: Problems in the chemical diagnosis of glycoprotein storage diseases. In: V. Zambotti, G. Tettamani. M. Arrigoni: Glycolipids, Glycoproteins and Mucopolysaccharides in Nervous System. pp. 281-291 (Plenum Press, New York, 1972).

24. Ornoy, A. Sekeles, E. Cohen, R.. and Kohn, G.: Electron microscopy of cultured skin fibroblasts and amniotic fluid cells in the diagnosis of hereditary storage diseases. Monogr. Hum. Genet., pp. 32 (1978).

25. Patel, V.: Degradation of glycoproteins. In: M. Horowitz W. Pigman: The Glycoconjugates. Vol. 2, pp. 188-229 (Academic Press, Inc., New York, 1978).

26. Philippart, M.: Glycolipid, mucopolysaccharide and carbohydrate distribution in

Copyright (C) 1980 International Pediatric Research Foundation, Inc.

$0031-3998 / 80 / 1411-1199 \$ 02.00 / 0$ tissues, plasma and urine from mucolipidoses and other disorders. Complex nature of the accumulated substances. In: V. Zambotti, G. Tettamani, M. Arrigoni: Glycolipids, Glycoproteins and Mucopolysaccharides of the Nervous System. (Plenum Press, New York, 1972).

27. Renlund, M. Chester, A. Lundblad, A., Aula, P., Raivio, K. O., Autio, S., and Koskela, S-L.: Increased urinary excretion of free $\mathrm{N}$-acetylneuramic acid in thirteen patients with Salla disease. Eur. J. Biochem., 101: 245 (1979).

28. Sipe, J. C., and O'Brien. J. S.: Ultrastructure of skin biopsy specimens in lysosomal storage diseases: common sources of error in diagnosis. Clin. Genet. 15: 118 (1979).

29. Thomas, G. H., Tiller, G. E., Reynolds, L. W., Miller, C. S., and Bace, J. W. Increased levels of sialic acid associated with a sialidase deficiency in I-cell disease (Mucolipidosis II) fibroblasts. Biochem. Biophys. Res. Commun., 7I: 188 (1976).

30. Tondeur, M., Vamos-Hurwitz, E., Mockel-Pohl, S., Dereume, J. P., Cremer, N. and Loeb. H.: Clinical, biochemical and ultrastructural studies in a case of chondrodystrophy presenting the I-cell phenotype in tissue culture. J. Pediatr. 79: 366 (1971)

31. Tsay, G., Dawson, G., and Matalon, R.: Glycopeptide storage in skin tibroblasts cultured from a patient with $\alpha$-mannosidase deficiency. J. Clin. Invest., 56: 711 (1975).

32. Virtanen, I., Ekblom, P., and Laurila, P.: Subcellular compartmentalization of saccharide moities in cultured normal and malignant cells. J. Cell. Biol. (in press).

33. The authors thank Lea Hakala, Raili Taavela, and Ritva Nurme-Helminen for their technical assistance.

34. Requests for reprints should be addressed to: Dr. 1. Virtanen, Department of Pathology. University of Helsinki, Haartmaninkatu 3, SF-00290. Helsinki 29. Finland.

35. This research was supported by grants from the Research Council for Medical Sciences, Academy of Finland. The Sigrid Juselius Foundation, and the Association of the Finnish Life Insurance Companies.

36. Received for publication March 7, 1980.

37. Accepted for publication May 9. 1980.

Printed in U.S.A. 